\title{
An Investigation of the Consequences and Imperatives for the Development of the Problem- Solving Skill of Saudi English Major Students in Online Classrooms
}

\author{
Nasser Alasmari \\ Department of English \& Translation, University of Jeddah, Jeddah, Saudi Arabia \\ Fahad Alkhamees \\ Department of English \& Translation, University of Jeddah, Jeddah, Saudi Arabia
}

\begin{abstract}
Based on the claim that problem-solving is one among other indispensable skills that $21^{\text {st }}$-century learners have to acquire and develop as it helps them face the increasingly intricate academic issues, especially at the tertiary level and due to the widespread pandemic that led to the resort to online learning as the only alternative available to guarantee the continuation of the learning process, the current work investigates the imperatives and consequences of problem-solving development in an online environment among Saudi English majors. It also examines the impact of online classrooms on Saudi academic learners and the difficulties they face. Whether online learning has provided the environment for students to thrive and develop their various skills or whether it has hindered their progress and negatively increased their reliance on technology with their skills and abilities, it also looks into the academic factor and the various impacts it has on students' language learning and skill development. 30 Saudi English majors in Jeddah University, Khulais faculty, contributed to the conduct of this research, which uses a mixed-method approach to get both the breadth and depth of the research. In addition to the study's theoretical work, it also shed light on the numerous challenges and obstacles that stand in the way of problem-solving skill development among learners.
\end{abstract}

Index Terms - problem-solving, Saudi Arabia, academic difficulties, online learning, COVID 19

\section{INTRODUCTION}

The rapid change in the academic environment from online classrooms to shifting work requirements has made it vital to look into different qualities among individual learners (Kutlu et al., 2010). Instead of individuals who are taught only to memorize a given data as it is common in the Saudi educational system, the potentials of those who can use, challenge, and discuss given information, as well as solve problems with it, has increased significantly (Alrabai, 2016; Şentürk \& Baş, 2010). Memorizing data that can be irrelevant in a short amount of time at our current rapidly advancing technology might be a thing of the past in favor of skills that enable individuals to endure, adapt, and solve problems they might face throughout their lives (Çevik, 2011). Accordingly, choosing and putting forward individuals who are skilled at problem-solving ability is one of the main goals of today's education (Kutlu et al., 2010; Çevik, 2011), and the development of such fundamental abilities and skills is critical for any modern comprehensive educational program that takes into consideration the real-world work environment, and the daily obstacles learners face during their lives. Such educational programs face a plethora of challenges in the rapidly changing academic and working environments, including the recent major shift to online learning and online workplaces caused by the COVID-19 pandemic that gave rise to numerous online platforms and applications that serve and cover the needs of learners, workers, and individuals from all walks of life. This raises many questions on the viability and usefulness of such platforms in the development of the problem-solving skill and whether our increased dependence on technology has impacted this vital skill in the Saudi Arabian academic context in more particular terms. In fact, in the traditional environment, the Saudi academic EF learners face many difficulties in academic writing and comprehension skills that hinder their academic performance (Alrabai, 2016; Alharbi, 2019).

In all fields, a problem is commonly defined as something unpleasant that deprives people of achieving their goals. The field of education is no exception, where both teachers and students frequently face different kinds of problems and are supposed to quickly solve them for the smooth continuation of the learning process. This led to the emergence of the terminology problem-solving skill, whose introduction to the classroom was as old as ancient times thanks to Socrates, who applied it. However, it was abandoned afterward till the 60s, when its revival started to take place, to receive a deeper recognition in the late 80s when it became very popular (Martinez, 1998). According to Doghonadze and Gorgiladze (2008), this skill is conceptualized as the ability to use existing knowledge and skills to address an 
unanswered question or solve a troubling situation. It refers to the skill of finding the main causes of a particular problem and the ability to formulate viable solutions to overcome it.

It is worth mentioning that the revival of problem-solving is, in fact, strictly intertwined with the gradual shrink of the role of the teacher and the move in focus towards the learners who have become more and more responsible for their learning and more actively engaged in education as they take individual decisions according to their needs and preferences. As such, today's learners are expected to acquire and develop all the skills needed to help them face contemporary challenges and thus develop productive education. Problem-solving is definitely one of these skills. With the sudden move to the digital learning mode in almost all over the world, including Saudi Arabia, an investigation of the consequences and imperatives for the development of the problem-solving skill of the Saudi English major students in online classrooms makes up the focus of the present paper.

\section{A. Statement of the Problem}

Much consideration has been given to the development of the learners' problem-solving skills, which comes as a response to the different challenges the 21 st-century requirements pose in the academic settings. Indeed, Rotherham and Willingham (2009) emphasized that with the bulk of the information available nowadays, the content itself is no longer important; the way of knowing and dealing with information is what really matters. The real issue that educationalists should focus on, according to the same authors, is to find out the appropriate ways to equip learners with the most suitable skills such as problem-solving and critical thinking that would allow them to reach content and thus improve their learning outcomes. With more challenges posed at the beginning of the academic year 2020 because of the emergence of coronavirus and the spread of the pandemic, which led to the total closure of the academic settings and the resort to the online teaching mode, the question of developing learners' skills becomes much more pressing. Is the online learning environment better than the traditional learning environments for the development of the problemsolving skill, or is the increased reliance on technology on our learning has negative repercussions on our mental abilities and skills such as the problem-solving one? These questions are what researchers around the world strive to answer.

\section{B. Rationale for the Topic}

With all the unprecedented circumstances caused by the widespread COVID-19 pandemic, which resulted in the total closure of schools and the resort to relatively unprepared and poorly established platforms for learning online, more charges and challenges that faced the academic institutions were added to the already existing ones. Saudi Institutions are considering the different ways possible in order to meet these challenges and help learners become well prepared and informed to succeed in their future jobs and become active members in their communities. Thus, educators are expected to equip their students with the different skills that allow them to achieve the aforementioned goals; problemsolving skills rank high in this respect.

\section{Scope of the Study}

Based on the claim that problem-solving is one among other indispensable skills that learners have to acquire and develop as it helps them face the increasingly intricate academic issues, especially at the tertiary level, the present research aims to identify both the consequences and the imperatives for the development of such skills among Saudi learners majoring in English who are currently taking their courses online which, in turn, confers more particularity on the study. Thus, an investigation of the consequences and imperatives for the development of the problem-solving skills among the Saudi English major students in online classrooms seems of relevance.

\section{Research Questions}

The current research is designed to answer the following questions:

a. What are the problem-solving skills acquired by Saudi students when learning online?

b. What are the consequences for the development of the problem-solving skill of Saudi English major students in online classrooms?

c. What are the imperatives for the development of the problem-solving skill of Saudi English major students in online classrooms?

d. How do Saudi learners' problem-solving skills develop when learning online?

\section{LITERATURE REVIEW}

In answer to the question "what is problem-solving?" Woods et al., (1997) claimed that it refers to the process followed to get the best answer to something unclear or to make a decision about a novel situation that is subject to some constraints. He postulated that the problem situation should be unknown to the learners and added that problemsolving necessitates too much mental effort. The same author stressed the difference between "problem-solving" and "exercise solving" and argued that the former term is more complicated while the latter simply indicates the recalling of standard solutions suggested to already solved problems. Problem-Solving skill is an active component in various fields from philosophy and medicine to computer science and artificial intelligence; therefore, a wide variety of definitions exists for each of these distinct fields. In the linguistic context, it refers to a conscious, inductive, and heuristic form of 
learning (Bourke, 1997).

Skilled problem-solvers can easily determine the source of the problem and identify practical solutions. It is also stated that this skill itself is intertwined with other skills such as communication, creativity, critical thinking, and active listening. According to Schoenfeld (2013), Problem-solving was generally defined as attempting to achieve some outcomes when there was no known method for trying to achieve that outcome (p.10). Woods et al., (1997), on the other hand, demonstrated thirteen attributes of problem-solving skills and claimed that if the learners developed them, they would obtain the best possible answer from the resources available.

a. While trying to solve the problem, learners should be aware of the processes being used.

b. Learners should use "pattern matching" in order to quickly figure out if the given situation is a problem or an exercise.

c. Learners should be able to apply a variety of strategies and heuristics.

d. Learners should demonstrate an adequate level of accuracy.

e. Learners should be very active in writing down ideas and creating charts and figures.

f. Learners should show great ability in writing down ideas, creating charts and figures

g. Learners should be able to monitor and reflect on the process to be applied in order to solve the given problem.

h. Learners should be well organized and systematic.

i. Learners should be flexible by conceptualizing the given situation from different perspectives.

j. Learners should be able to draw on the pertinent information they have about the subject and assess it in an objective, critical way.

k. Learners should display the ability and willingness to manage stressful situations and face the challenge.

1. Once they identify the situation as a problem, learners should show their willingness to go through the process of spending time reading, collecting data, and identifying the problem.

m. Learners should not resort to already memorized solutions for previous solutions but try to follow a particular approach to solve the present situations.

These attributes, as claimed by Woods, et al., (1997), are what characterize the different skills learners need to develop.

Hassan and Ahmad (2015) conducted a research about the availability of problem-solving skills among Saudi students in Special Education. They emphasized the importance of these skills in helping learners manage the challenging and pressing situations they face in their day-to-day lives. They argued that a skilled problem solver is someone who is able to first identify, evaluate and divide the unpleasant situations into different elements, then react faster while brainstorming the possible ways to handle and solve these situations, to end up with the analysis of results. The same authors came up with the conclusion that problem-solving mainly involves the following skills, which they consider as keys to problem-solving as "analytical ability, lateral thinking, initiative, logical reasoning, and persistence" (p.15).

When it comes to developing problem-solving skills, Gyula (2016) reckoned that the way how students end up being successful problem solvers is subject to "the ability of the teacher to gauge the abilities of the students and to fit it the level of difficulty of the problems which is vital in the course of teaching and problem-solving" (p. 2). He added that the real change lies in the hands of the learners themselves and in their willingness to indulge in the problem and solve it. He asserted that by doing this, the real achievement would take place not only at the academic level through better and significant performance in the short run but also at later stages after graduation in preparing them for future careers. Additionally, the extensive use of technology that characterizes the world today makes it indispensable for learners to acquire it so as to perform tasks related to their fields of study. The technological knowledge the students come to acquire and develop is said to help them improve their problem-solving skills.

The problem-solving process always centers around the problem. Students, during the problem-solving process, apply analytical and creative thinking skills to previous knowledge. The final outcome is generally some sort of a decision, in other words, the choosing and assessing of a solution. According to Blanchard-Fields (2007), two general types of problems exist. Those with known solutions upon which students can apply a similar methodology to one they have already used are called close-ended problems. For instance, if a student understands the single-digit method of adding two plus two create four, he would most likely be able to solve a problem that asks him to add one plus one. On the other hand, open-ended or loosely structured problems are those with multiple or uncertain solutions rather than one right answer. These kinds of problems require the ability to apply a variety of different methods and knowledge to come up with a solution. Many courses, educators, and exams show or request just the problem-solving outcomes and not the whole process that students have to go through in learning about how to reach a feasible solution. As a result, most individuals use their personal understanding to try to address open-ended issues, but the bias of limited knowledge makes it difficult for individuals to understand the trade-offs or inconsistencies that these issues present. Therefore, students need to be able to use both problem-solving abilities and an efficient inquiry mechanism to solve specific problems.

\section{METHOD}

\section{A. Participants}


The study participants consist of thirty Saudi EFL applied linguistics majors from the University of Jeddah, Khulais branch. Participants represent a variety of age groups, schooling level, genders, EFL experience, as well as social and regional backgrounds. 21 (70 percent) of the participants were women, and 9 (30 percent) were men. About 10 (33.3 percent) aged 20 - 29 years, about 12 (40 percent) aged $30-40$ years, about 8 (26.7 percent) aged more than 40 years. Sixty-seven percent were not traveled, and 33 percent were traveled outside the country.

\section{B. Instruments}

Two instruments are employed in collecting this study data. These were in the form of a multiple-choice questionnaire (appendix A), and an in-depth interview (appendix B).

\section{Data Collection Procedure \& Rationale}

Study participants are to complete their tasks when they are available. The first task was the multiple-choice questionnaire which consists of four themes and twenty randomized questions that are scaled from one to five in terms of agreement. Then, the participants partake in interview questions that require short-form and long-form answers.

A mixed-method approach is adopted because combining qualitative and quantitative research allows for a more indepth understanding of the obscure details of quantitative data, as well as a more practical and insightful analysis (Alasmari, 2020).

The questionnaire includes four themes, namely; a) proficiency and interest, which reflects the participants' desire and motivation to contribute to their field of learning a foreign language as well as their views concerning their abilities to be proficient, b) the academic side, which consists of gathering knowledge of Saudi majors' difficulties as well as determining if the university and the academic system in the country hindered their learning progress or any of their problem-solving skills, c) problem-solving, and d) online learning.

The interview is also used in order to get a better insight into how learners approach problems that could arise in their conventional learning or when they are learning online. The main focus of the interview is first on the problem-solving skills, online classrooms, the academic environment, as well as the difficulties the participants faced in their learning. In the problem-solving section, learners' prior knowledge of the problem-solving skill as well as their community interest in its development is one of the main focal points, their use and understanding of problem-solving skills are also examined in the educational setting. The online section, on the other hand, focuses on the learners' dependency of their mental skills on technology in online classrooms as well as their views and perspectives in the online learning process and if it is more relaxing than the traditional counterpart and whether that helped or hindered their mental skills developments.

In their academic environment, we look if the various academic institutions the participants went to had helped them understand and develop their mental skills, such as the problem-solving skill, as well as look into their prior experience and impressions of the academic environment and if it was an encouraging place to develop their mental skills or not. Moreover, in their difficulties section, revealing obstacles learners faced throughout their mental skills developments is the main focus of this section, and also look into their points of view on the place of the relevant issues as well as their views on what the appropriate solutions are according to them.

The interview questions and answers have two forms, first is the short-form in which participants can answer with yes or no, which should gradually increase their desire to express themselves. Then is the long-form, which gives learners a chance to answer with as much as they want; this should provide their whole perspective on all the given aspects of the questions as well as being able to share some not-so-obvious points that can be absent to researchers and observers.

\section{Data Analysis \& Reliability Diagnostics}

The Cronbach's alpha was used to assess whether the 5 items used to measure each of the four themes on the questionnaire are reliable or not. As table 1 below indicates, proficiency and interest Cronbach's alpha were found to be 0.884 , which is a high number and thus, the 5 items used to measure proficiency and interest are reliable. The same holds true for the rest of the themes as it equals 0.913 for the academic achievement, 0.946 for problem-solving, and 0.832 for online learning.

TABLE 1

VALUES OF CRONBACH'S ALPHA RELIABILITY COEFFICIENT FOR THE SURVEY SCALES

\begin{tabular}{|c|c|c|}
\hline Scale & Cronbach's Alpha & Number of items \\
\hline proficiency and interest (Items 1-5) & 0.884 & 5 \\
\hline academic achievement (Items6-10) & 0.913 & 5 \\
\hline problem-solving (Items 11-15) & 0.946 & 5 \\
\hline online learning (Items 16-20) & 0.832 & 5 \\
\hline
\end{tabular}




\section{FINDINGS}

Study results are divided into two main sections, quantitative and qualitative, to have the full scope and depth of the study's findings. Various methods have been utilized in the analysis process to give a clear picture of the study findings. Such methods significantly contribute to the study's validity and reliability, which will assist future research in problemsolving, students' language proficiency, academic and online learning.

\section{A. Quantitative Results}

Characteristics of the distributions of the participants' answers were obtained by calculating means and standard deviations for each item on the questionnaire as displayed in table 2, which also shows the information collected and analyzed by the researcher based on student's opinion towards proficiency and interest, academic achievement, problem-solving and online learning, based on 5- point Likert Scale, $(1=$ Strongly disagree, $2=$ Disagree, $3=$ Not sure, 4= Agree, 5 = Strongly agree).

TABLE 2

DESCRIPTIVE STATISTICS

\begin{tabular}{|c|c|c|c|c|c|}
\hline Items & $\mathrm{N}$ & Minimum & Maximum & Mean & Std. Deviation \\
\hline \multicolumn{6}{|c|}{ Proficiency \& Interest } \\
\hline I feel I am proficient in English & 30 & 1.00 & 3.00 & 2.0667 & .63968 \\
\hline Learning English is very important & 30 & 1.00 & 2.00 & 1.1333 & .34575 \\
\hline Linguistics as a major is very interesting & 30 & 1.00 & 4.00 & 2.0000 & .78784 \\
\hline Learning English is hard & 30 & 2.00 & 5.00 & 3.6333 & .99943 \\
\hline I am interested in Learning English & 30 & 1.00 & 2.00 & 1.3667 & .49013 \\
\hline \multicolumn{6}{|c|}{ Academic achievement } \\
\hline There are difficulties when writing academically & 30 & 1.00 & 4.00 & 2.2000 & .80516 \\
\hline The academic field in Saudi Arabia needs improving & 30 & 1.00 & 3.00 & 1.5333 & 68145 \\
\hline I like reading and writing for academic purposes & 30 & 1.00 & 4.00 & 2.0000 & .69481 \\
\hline Improving academic writing is necessary & 30 & 1.00 & 2.00 & 1.4333 & .50401 \\
\hline Academia is very important to me & 30 & 1.00 & 4.00 & 1.7667 & .85836 \\
\hline \multicolumn{6}{|c|}{ Problem solving } \\
\hline I am good at solving problems & 30 & 1.00 & 3.00 & 1.7000 & .59596 \\
\hline The university improved my problem-solving ability & 30 & 1.00 & 4.00 & 2.6333 & .92786 \\
\hline I use problem-solving strategies for learning & 30 & 1.00 & 4.00 & 1.9333 & 69149 \\
\hline I am interested in Improving my problem-solving skills & 30 & 1.00 & 3.00 & 1.8000 & .61026 \\
\hline I think solving problems is important in learning languages & 30 & 1.00 & 3.00 & 1.8000 & .61026 \\
\hline \multicolumn{6}{|c|}{ Online Learning } \\
\hline Online learning increased my dependence on technology & 30 & 1.00 & 4.00 & 1.6667 & .80230 \\
\hline My writing has improved with online learning & 30 & 1.00 & 5.00 & 2.7000 & 1.05536 \\
\hline Online classrooms hinder my learning & 30 & 2.00 & 5.00 & 3.4667 & 1.04166 \\
\hline Writing and reading online is more comfortable & 30 & 1.00 & 5.00 & 2.2667 & .98027 \\
\hline I like learning online & 30 & 1.00 & 5.00 & 2.1000 & .95953 \\
\hline
\end{tabular}

In general, there was positive feedback from respondents in relation to proficiency and interest, with a high level of agreement for most of the items. More specifically, learning English is hard, Linguistics as a major is very interesting are rated high by the student respondents.

On the other hand, it was found that it is a big challenge for the Blackboard administration to exert all efforts needed to enhance the student's capability so as to be able to solve their problems, which is their ultimate goal, that online learning and problem solving are rated very low (Mean of 2) in general, which means that the students disagreed. As concerning academic achievement, this variable was rated very low. More specifically, the students did not agree that academia is very important to them, improving academic writing is necessary. Also, they do not like reading and writing for academic purposes.

\section{Proficiency and Interest}

This section examines learners' own perceived level of knowledge as well as their desire to learn and improve in their respective field in simple and understandable words. As is shown in the first question, the majority feel they are proficient in the English language with a total agreement of 23, which makes up 76.7 percent of the total. Only 7 are neutral and no disagreement, which indicates confidence in the language level.

This segment received $100 \%$ agreement which further indicates the informants' interest in the given language and 
their field that includes learning and teaching English. In this segment, a high agreement of 83 percent is counted; however, disinterest in linguistics is still present with a 10 percent neutral and 6.7 disagreements from the overall sample. In fact, most of the participants do not believe that learning the English language is hard, with $60 \%$ disagreements and a 23.3 neutral, which further indicates interest and confidence in their field, but some agreements do exist with 16.7 of the overall percentage. The learners further demonstrated high interest in enhancing and improving their language skills and abilities with a $100 \%$ agreement rate on their interest in learning the language, which may suggest a welcoming attitude for any future improvements to their learning abilities of the language and its relevant aspects.

TABLE 3

PROFICIENCY AND INTEREST

\begin{tabular}{|c|c|c|c|c|c|}
\hline Items & 1 & 2 & 3 & 4 & 5 \\
\hline I feel I am proficient in English & 5 & 18 & 7 & 0 & 0 \\
\hline Learning English is very important & 26 & 4 & 0 & 0 & 0 \\
\hline Linguistics as a major is very interesting & 7 & 18 & 3 & 2 & 0 \\
\hline Learning English is hard & 0 & 5 & 7 & 12 & 6 \\
\hline I am interested in Learning English & 19 & 11 & 0 & 0 & 0 \\
\hline
\end{tabular}

\section{Academia}

The second central theme of the questionnaire is academia which investigates learners' perceptions, abilities, perceived achievements, and obstacles that prevent them from improving. According to the table below, a majority of participants find difficulties in academic writing, with 76.6 percent agreements and 13.3 percent uncertain. 10 percent minority do not have such difficulties; this implies the need to improve academic writing skills. On the other hand, 90 percent of the informants agree on improving the academic field in Saudi Arabia with no disagreements, while 10 percent are uncertain. This reflects their dissatisfaction with the current model and the need to improve it among academics. A vast majority of 83.3 percent do indeed like writing for academic purposes, so the difficulties in writing are not due to the lack of desire. However, 3.3 percent do not like to write for this purpose as well as 13.3 percent are uncertain. This further indicates the need for ways to improve their academic writing output with a 100 percent agreement rate. In addition, a vast majority of 86.6 percent view academia as an important aspect to them which also suggests that it is not necessarily the lack of desire that hinders them; however, 6.7 percent disagree, and another 6.7 percent are uncertain.

TABLE 4

ACADEMIA

\begin{tabular}{|c|c|c|c|c|c|}
\hline Items & 1 & 2 & 3 & 4 & 5 \\
\hline There are difficulties when writing academically & 4 & 19 & 4 & 3 & 0 \\
\hline The academic field in Saudi Arabia needs improving & 17 & 10 & 3 & 0 & 0 \\
\hline I like reading and writing for academic purposes & 6 & 19 & 4 & 1 & 0 \\
\hline Improving academic writing is necessary & 17 & 13 & 0 & 0 & 0 \\
\hline Academia is very important to me & 13 & 13 & 2 & 2 & 0 \\
\hline
\end{tabular}

\section{Problem-solving}

The third central theme is problem-solving, which investigates and examines possible variables that may affect this crucial ability growth and development among academic learners. As the table below indicates, the vast majority perceive themselves as good at solving problems with 93.4 percent agreement while 6.6 percent are uncertain. A slight majority of 53.4 percent believe that the university has improved their problem-solving ability, while 23.3 percent disagree, and the same percentage is uncertain. The table also demonstrates that learners with 86.6 percent majority use some sort of problem-solving strategies to improve their learning which shows the usefulness and importance of developing better strategies; however, 3.3 percent disagree, and 10 percent are uncertain. It is also indicated that there is an immense desire to improve and develop this essential skill with a 90 percent agreement rate and no disagreements. It may also imply students' interest in developing mental capabilities, however 10 percent uncertain. Besides, a vast majority of 90 percent think problem-solving is important when learning a language. Their view reflects the significant role problem-solving skills play in learning languages, worth noting 10 percent are uncertain.

TABLE 5

PROBLEM-SOLVING

\begin{tabular}{|c|c|c|c|c|c|}
\hline Items & 1 & 2 & 3 & 4 & 5 \\
\hline I am good at solving problems & 11 & 17 & 2 & 0 & 0 \\
\hline The university improved my problem-solving ability & 2 & 14 & 7 & 7 & 0 \\
\hline I use problem-solving strategies for learning & 7 & 19 & 3 & 1 & 0 \\
\hline I am interested in Improving my problem-solving skills & 9 & 18 & 3 & 0 & 0 \\
\hline I think solving problems is important in learning languages & 9 & 18 & 3 & 0 & 0 \\
\hline
\end{tabular}




\section{Online Learning}

The fourth central theme is online learning, which aims to identify and investigate the role online learning plays on their mental abilities and if they have difficulties in this new learning environment. As the table below displays, the vast majority of 86.7 percent believe that online learning increased their dependence on technology which may imply that there is an over-reliance on modern technology. However, a minor 3.3 percent disagree, and 10 percent are uncertain. A tiny majority of 50 percent believe online learning improved their writing output. However, we cannot conclude anything solid from this as the other 50 percent are either in disagreement or uncertain, 26.6 disagree, and 23.3 are uncertain. A great majority of 80 percent like learning online, which may imply that this new learning environment is more desirable for them; however, 10 percent disagree with that, and the other 10 are uncertain. 53.2 percent, disagree with the notion that online classrooms hinder their learning, and only 23.3 percent agree, while the other 23.3 percent are uncertain. This indicates that online classrooms may not be a challenging change for most students to adapt and overcome as it might be a much smoother change than what one may assume. In addition, a substantial majority of 73.4 percent believe that writing and reading online is more comfortable, 10 percent disagree, and 13.3 percent are uncertain. This may entail that online learning becomes a more relaxed environment than regular classrooms for the student.

TABLE 6

ONLINE LEARNING

\begin{tabular}{|c|c|c|c|c|c|}
\hline Items & 1 & 2 & 3 & 4 & 5 \\
\hline Online learning increased my dependence on technology & 15 & 11 & 3 & 1 & 0 \\
\hline My writing has improved with online learning & 3 & 12 & 7 & 7 & 1 \\
\hline Online classrooms hinder my learning & 7 & 17 & 3 & 2 & 1 \\
\hline Writing and reading online is more comfortable & 0 & 7 & 7 & 11 & 5 \\
\hline I like learning online & 5 & 17 & 4 & 3 & 1 \\
\hline
\end{tabular}

\section{B. Qualitative Results the Interview}

In the interview phase, there are three main variables that each has four questions; three of them can be answered with short-form answers such as yes or no, and one with only long-form answers with an unlimited number of words. The variables are Problem-solving, Academic environment, and Online learning.

In the first variable, the first short-form question asks if the participants ever sensed the significance of problemsolving skills during their study years; the majority stated "yes" while a minority of four stated "no". In the second question, which asks if the schools they attended showed some interest in their ability to solve problems, the majority also states "yes" while a minority of five stated "no". And in the third question that asks if they ever used any problemsolving strategy in their studies; the majority answered with "yes" while a minority of five stated "no". The last question of the problem-solving variable is a long-form one that asks if there is interest among their community in developing problem-solving skills: the majority are in disagreement, generally stating there is no interest in the problem-solving skill in their communities. However, a minority of four answered in agreement, one of them stating, "As one of the 21-century learning skills, it has become evident that society in general has taken an interest in problemsolving among other skills" and another stating, "Yes, as educational institutions have recently prepared courses to solve educational problems by developing appropriate plans and strategies that help in developing educational skills".

In the second variable, the first short-form question asks if the university environment developed their problemsolving abilities; half of the participants disagree with that, and the other half agree, no clear majority here. The second long-form question asks, with their previous experiences in mind, was the university environment nourishing their problem-solving skill development; the majority are in disagreement, some of them stating, "No, universities have nothing to do with developing problem-solving skills, but rather personal motivation and mental ability" as well as "I do not think so ... I gained the skill of solving problems from life experiences more than studying itself" while a minority of five are in agreement, one of them stating "Yes, the university prepared a domain under the name of the Student Council to listen to the problems of male and female students and solve them". The third question, which is a short-form one, asks whether the universities in Saudi Arabia gave them the opportunity to develop problem-solving skills at any point; the majority stated "no" while a minority of nine stated "yes" which may indicate an opportunity for the development of their mental skills is needed. And the last short-form question asks whether they believe there are obstacles to developing their problem-solving skills in the university environment; the majority stated "yes" while a minority of eleven stated "no" this may imply the need for universities to give the students more chances to express the obstacles they face and solve them.

In the third variable, the first short-form question asks whether online learning affected their ability to solve problems; the majority answered with "no" while a minority of ten stated "yes". The second short-form question asks if online learning made it easy for them to identify and solve their study problems; the overwhelming majority stated "yes" while a minority of five stated "no" which may indicate the mental benefits that online learning technology may bring. The third short-form question asks whether the online learning environment increased their reliance on technology with their cognitive skills; the majority answered with "yes" while a minority of seven stated "no" which may indicate students' self-awareness of the increasing mental reliance on modern technology. The final long-form question asks whether they think online learning has positive qualities for their mental abilities; the majority are in 
agreement, some of them stating, "Of course, because with online learning I gained problem-solving ability. Apart from that, it is calmer and gives me a chance to focuses on my abilities, strengths and weaknesses" as well as "Yes absolutely; I have developed many skills to use technology for education" while a tiny minority of three are in disagreement one of them stating "Face to face interaction is much more engaging to the mind of the learner".

\section{DISCUSSION}

Problem-solving skill development in Saudi majors' online classrooms was investigated, and the results showed high confidence in their language levels as well as in their mental abilities. It reveals obstacles and difficulties learners face in the academic environment. Results also showed their high dissatisfaction with the current Saudi academic process and environment. Learners were also found to hold positive views of online classrooms as they cited numerous benefits on their academic and mental skills, such as the Problem-solving. Findings of the current research are somewhat in line with Tuzlukova \& Usha-Prabhukanth (2018)'s which foregrounded the significance of mental skills such as critical thinking and the benefits it can provide, including students' increased self-confidence. It is worth noting, however, that multiple factors might be at play here, which can have an influence on our results, such as the fact that the majority of the respondents are females, as well as the largest age group being over thirty, and that some of the respondents indeed traveled outside Saudi Arabia to English speaking countries which may not reflect a complete representation of the country's educational output in the English language side of this study.

Findings also revealed an almost unanimous agreement and desire (92\%) from the part of the participants to improve their mental skills, such as their problem-solving ability, as well as developing their academic writing, online classrooms, and language learning. Nonetheless, there is also an almost unanimous disagreement on English language learning being hard or online classroom hindering their learning. These general perspectives may also reflect that the online environment is more comfortable and less anxious to learn than traditional classrooms.

In terms of proficiency and interest, nearly all participants showed a high degree of confidence in their English language ability; thus, the lack of motivation may not be an influential factor in this context. They also agreed on the importance of learning foreign languages such as the English language, which they do not perceive as challenging to learn and understand. This explains the high disagreement among them about the English language being hard.

As far as the academic side is concerned, findings showed that learners are having difficulties in their academic life, as well as some dissatisfaction with the current Saudi academic system and institutions. However, a high degree of interest in the improvement and advancement of their academic abilities, such as their writing for academic purposes, was reported. In fact, the majority of participants had challenges when writing academically; in the Arab FLL context, it sides with numerous studies around this issue in recent years (Al Fadda, 2012, Al Murshidi, 2014), which can be linked to multiple factors, including educational, motivational, and even a social one (Al Khairy, 2013) as well as to other know well-studied issues when learning foreign languages such as code-mixing and language transfer.

When it comes to problem-solving, the participants articulated high confidence in their problem-solving ability, with the majority $(93.3 \%)$ believing they are good with their ability to solve any given problem. They slightly agreed on the belief that universities are an aiding factor in their problem-solving skill improvements. Broad problem-solving strategies are numerous, as asserted previously in the literature review section; however, it is not unfathomable that a learner comes up with his own unique problem-solving strategy, which was the case here with the majority of participants stating that they indeed use problem-solving strategies in their learning. In addition, an overwhelming majority of the participants also expressed their interest in improving their problem-solving abilities. This outcome is constant with Samson (2015)'s conclusion that the majority of students have a high interest in problem-solving in their learning.

As for online learning, most of the participants acknowledged that it indeed increased their dependence on technology. Evidently, the increased reliance on technology is hard to deny in the educational sector, especially during the COVID-19 pandemic. Total shutdowns in Saudi Arabia forced the majority of all educational institutions to go online. With students studying at home, the need for more modern technology in all aspects of their learning has become a must; this reliance can have multiple psychological effects on the learners' mental skills and abilities, as numerous recent studies showed (Irawan, Dwisona \& Lestari, 2020; Saddik, et al., 2020). Which can negatively impact their problem-solving development; nonetheless, half of the participants agreed that online learning improved their writing. This can be due to more time available when learning at home to further develop the various skills and abilities that help in the learning process. The most disagreement was on the notion that online classrooms hindered learning, which is not their belief. This also further indicates the positive view learners have on the online learning environment. Participants also overwhelmingly agreed that reading and writing online is more comfortable; this demonstrates that wiring and reading online might have less anxiety involved than in the traditional way of reading and writing. It further shows how preferable online classrooms are, as the majority also stated that they like learning online. These findings are confirmed through the results obtained from the interview. Indeed, the majority of participants expressed their views on the significance of problem-solving skills in an academic and linguistic context; this shows that they prefer the online classroom environment and cited the numerous benefits it provided for them in learning and developing their mental skills. Also, most of the students reported negatively on the Saudi academic and university environment in the development of their mental skills, such as the problem-solving skill. Academically, they reported difficulties and 
obstacles within the academic system and environment that hinder their learning and problem-solving skill development. Mixed responses on if the university helped develop their mental skills were reported. This reflects the multiple challenges the academic system is facing, which is in line with numerous studies on this issue (Alharbi, 2019). In addition, most of the participants showed that their communities lack interest in and have knowledge of the problemsolving skill.

\section{LIMITATIONS}

Despite its informing findings, the current work is confounded by a number of issues, namely; the scarcity of references and related literature: despite its particularity, the current research suffers from the lack of documents that link the three variables under focus, namely; problem- solving skills, their development, and the online setting which lays the ground for more contemporary researches to be carried out in order to enrich the literature on the topic. In addition, carrying out the research with online instruments, namely online questionnaires and interviews may affect the students' responses and reduce the reliability of results. Thus, using a third data collection instrument would have conferred more validity on the findings obtained. Lastly, the subjects contributing to this research are 30 students majoring in English. Choosing one category of Saudi students in a limited setting, the Khulais branch (Jeddah University), which may constitute a shortcoming of the study that prevents the results from being generalized.

\section{CONCLUSION}

The work presented in this study suggests multiple conclusions regarding learners' language proficiency, interest, academic environment, problem-solving ability, and online learning. In their language proficiency, the data shows high confidence among learners in their language learning ability. Therefore, the lack of confidence may not have a substantial role in their problem-solving development with the given context. Moreover, the data reveals the learners' high interest in their language learning and online learning. This indicates that it may not be learners' lack of interest that hinders their progress. However, in the academic environment, learners showed considerable discontent citing the numerous challenges and difficulties they faced. These difficulties may be one of the main factors that hampered their problem-solving ability. This indicates a crucial need for further independent research on these difficulties that may lead to the root cause of one of the main challenges to learners' problem-solving development. Moreover, it was also found that learning online is more desirable and comfortable for students. The relaxed environment of online classrooms may positively impact learners' mental skills development, such as their problem-solving ability.

It is imperative for universities to address the numerous challenges learners face to create an environment where they can communicate and recognize the difficulties they encounter during their learning. Recognizing and identifying the challenges they face is one of the first steps to developing students' various skills and abilities. This includes having a place where students can easily present the difficulties they face, as well as having the means to resolve them rapidly. It is also important to note that these difficulties may not be due to the lack of involvement but rather to the overinvolvement of college administrations that may have complicated students' learning. It is critical for universities to be transparent with their students and not stand in the way of their development. In order to better understand the learning challenges that hinder students' problem-solving ability not only in the academic context but also in their daily lives, we should always provide the opportunity for them to express these difficulties that discourage any further development of their skills.

\section{REFERENCES}

[1] Alasmari, N. (2020). Mixed Methods Research: An Overview. International Journal of Social Science and Human Research, 3 (9), 147-154.

[2] Al Fadda, H. (2012). Difficulties in Academic Writing: The Perspective of King Saud University Postgraduate Students. English Language Teaching, 5(3), 123-130.

[3] Alharbi, M. A. (2019). Saudi Arabia EFL university students' voice on challenges and solution in learning academic writing. Indonesian Journal of Applied Linguistics, 8(3), 576-587.

[4] Al Khairy, M.A. (2013). Saudi English-Major Undergraduates' Academic Writing Problems: A Taif University Perspective. English Language Teaching, 6 (6), 1-12.

[5] Al Mrushidi, G.H. (2014). Emirati and Saudi Students' Writing Challenges at U.S. Universities. English Language Teaching 7(6), 87-95.

[6] Alrabai, F. (2016). Factors underlying low achievement of Saudi EFL learners. International Journal of English Linguistics, 6(3), 21-37.

[7] Bas, G, and Senturk, C. (2010). Perceptions of teachers about the curriculum: A metaphor analysis. Research in Pedagogy, 10(2), 338-353.

[8] Blanchard-Fields, F. (2007). Everyday Problem Solving and Emotion: An Adult Developmental Perspective. Current Directions in Psychological Science, 16(1), 26-31.

[9] Bourke, J. M. (1996). In praise of linguistic problem-solving. RELC journal, 27(2), 12-29.

[10] Cevik, D. B. (2011). Problem Solving Skills by Music Teacher Candidates Several Variables. Kastamonu Education Journal, 19(3), 1003-1012.

[11] De Bono, E. (1985). Six Thinking Hats. London: Penguin Books. 
[12] Doghonadze, N., and Gorgiladze, G. (2008). Problem solving in teaching foreign languages to students of pedagogical departments. IBSU Scientific Journal, 2(1). 101-114.

[13] Funkhouser, C., \& Dennis, J. R. (1992) The Effects of Problem-Solving Software on Problem-Solving Ability. Journal of Research on Computing in Education, 24(3), 338-347.

[14] Gyula. N.G. (2016). Developing Problem-solving Skills. Retrieved January 6th, 2021 from; file://C:/Users/acer/Downloads/DevelopingProblemsolvingSkillsGyNKRG.pdf

[15] Hassan, A.H., and Ahmad, E. Y. (2015). The Availability of Solve Problems Skills among students in Special Education Faculty of Education, University of Jazan, Saudi Arabia. International Research Journal for Quality in Education, 2(2), 15-21.

[16] Irawan, A. W., Dwisona, D., \& Lestari, M. (2020). Psychological Impacts of Students on Online Learning during the Pandemic COVID-19. KONSELI: Jurnal Bimbingan dan Konseling (E-Journal), 7(1), 53-60.

[17] Kutlu, Ö., Doğan, C. D., \& Karakaya, İ. (2010). Öğrenci başarısının belirlenmesi performansa ve portfolyoya dayalı durum belirleme [Determining student success by determining the situation based on performance and portfolios]. Ankara, Turkey: Pegem Akademi Yayınları.

[18] Martinez, M.E. (1998). What is Problem Solving? Phi Delta Kappan, 79 (8), 605-609.

[19] Roll, I., Baker, R. S. D., Aleven, V., \& Koedinger, K. R. (2014). On the benefits of seeking (and avoiding) help in online problem-solving environments. Journal of the Learning Sciences, 23(4), 537-560.

[20] Rotherham, A.J., and Willingham, D. (2009). 21st Century Skills: The Challenges Ahead. Teaching for the 21st Century, 67(1), 16-21.

[21] Saddik, B., Hussein, A., Sharif-Askari, F., \& Kheder, w., Temsah, M.A., Koutaich, R., Haddad, E., Al-Roub, N., Marhoon, F., Hamid, Q., \& Halwani, R. (2020). Increased levels of anxiety among medical and non-medical university students during the COVID-19 pandemic in the United Arab Emirates. Dovepress, 3, 2395- 2406.

[22] Samson, D. (2015). Devising explorative Euclidean Geometry questions. Learning and Teaching Mathematics, 2015(19), 1316.

[23] Schoenfeld, A. H. (2013). "Reflections on Problem Solving Theory and Practice," The Mathematics Enthusiast: Vol. 10: No. 1, Article3. Retrieved January 7th, 2021, at: https://scholarworks.umt.edu/tme/vol10/iss1/3

[24] Tuzlukova, V., \& Usha Prabhukanth, K. (2018). Critical thinking and problem-solving skills: English for science foundation program students' perspectives. Collection of papers of the faculty of philosophy of the University of Pristina, XLVIII (3), 3797.

[25] Tuzlukova, V., \& Usha-Prabhukanth, K. (2018). Critical thinking and problem-solving skills: English for science foundation program students' perspectives. Zbornik radova Filozofskog fakulteta u Prištini, 48(3), 37-60.

[26] Woods, D.R., Hrymak, A. N., Marshall, R.R., Wood, P.E., and Crowe, C.M. (1997). Developing Problem Solving Skills: The McMaster Problem Solving Program. Journal of Engineering Education, 86(2), 75-91.

Nasser Alasmari holds a PhD in Linguistics from UON, New South Wales, Australia. His areas of interest and research are in the cognitive and contrastive analysis and his main research area is cross-cultural perceptions which he formalised in a number of his current research on this subject. He has taught Applied Linguistics, Sociolinguistics, and semantics. He has presented papers at conferences both home and abroad, published articles and papers in various journals, and contributed as a reviewer in several language and linguistics conferences.

Fahad S. Alkhamees is currently a Master graduate in Applied Linguistics from the University of Jeddah. He received a bachelor's degree in English from Majmaah University, Saudi Arabia. He worked as an English teacher (for high school level learners). His research interests include EFL skill development. 